\title{
Measuring visual cortical oxygenation in diabetes using functional near-infrared spectroscopy
}

\author{
Ross T. Aitchison ${ }^{1} \cdot$ Laura Ward $^{2} \cdot$ Graeme J. Kennedy $^{1} \cdot$ Xinhua Shu $^{1} \cdot$ David C. Mansfield $^{3} \cdot$ Uma Shahani $^{1}$
}

Received: 23 April 2018 / Accepted: 25 July 2018 / Published online: 6 August 2018

(c) The Author(s) 2018

\begin{abstract}
Aims Diabetes mellitus affects about $6 \%$ of the world's population, and the chronic complications of the disease may result in macro- and micro-vascular changes. The purpose of the current study was to shed light on visual cortical oxygenation in diabetic individuals. We then aimed to compare the haemodynamic response (HDR) to visual stimulation with glycaemic control, given the likelihood of diabetic individuals suffering from such macro- and micro-vascular insult.

Methodology Thirty participants took part in this explorative study, fifteen of whom had diabetes and fifteen of whom were non-diabetic controls. The HDR, measured as concentrations of oxyhaemoglobin [HbO] and deoxyhaemoglobin [HbR], to visual stimulation was recorded over the primary visual cortex (V1) using a dual-channel oximeter. The stimulus comprised a pattern-reversal checkerboard presented in a block design. Participants' mean glycated haemoglobin $\left(\mathrm{HbA}_{1 \mathrm{c}}\right)$ level $( \pm \mathrm{SD})$ was $7.2 \pm 0.6 \%$ in the diabetic group and $5.5 \pm 0.4 \%$ in the non-diabetic group. Raw haemodynamic data were normalised to baseline, and the last $15 \mathrm{~s}$ of data from each 'stimulus on' and 'stimulus off' condition were averaged over seven duty cycles for each participant.

Results There were statistically significant differences in $\Delta[\mathrm{HbO}]$ and $\Delta[\mathrm{HbR}]$ to visual stimulation between diabetic and non-diabetic groups $(p<0.05)$. In the diabetic group, individuals with type 1 diabetes displayed an increased $[\mathrm{HbO}](p<0.01)$ and decreased $[\mathrm{HbR}](p<0.05)$ compared to their type 2 counterparts. There was also a linear relationship between both $\Delta[\mathrm{HbO}]$ and $\Delta[\mathrm{HbR}]$ as a function of $\mathrm{HbA}_{1 \mathrm{c}}$ level $(p<0.0005)$.

Conclusions Our findings suggest that fNIRS can be used as a quantitative measure of cortical oxygenation in diabetes. Diabetic individuals have a larger HDR to visual stimulation compared to non-diabetic individuals. This increase in $\Delta[\mathrm{HbO}]$ and decrease in $\Delta[\mathrm{HbR}]$ appears to be correlated with $\mathrm{HbA}_{1 \mathrm{c}}$ level.
\end{abstract}

Keywords Haemodynamic response $\cdot$ Functional near-infrared spectroscopy $\cdot$ Visual cortex $\cdot$ Diabetes $\cdot$ Autonomic dysfunction

Managed by Massimo Federici.

Ross T. Aitchison

ross.aitchison@gcu.ac.uk

1 School of Health and Life Sciences, Glasgow Caledonian University, Glasgow, UK

2 Institute of Health and Wellbeing, University of Glasgow, Glasgow, UK

3 Department of Ophthalmology, Inverclyde Royal Hospital, Greenock, UK

\section{Introduction}

Diabetes mellitus affects about $6 \%$ of the world's population, and the chronic complications of the disease may result in both life- and sight-threatening macro- and micro-vascular insult. It is estimated that 415 million people worldwide are currently affected by diabetes, and this number is projected to increase to 642 million by 2040 [15]. Type 1 diabetes accounts for approximately $5-10 \%$ of cases of diabetes; type 2 diabetes accounts for the remaining $90-95 \%$ of cases [1].

Diabetes damages not only the anatomy but also the physiology of the individual. Many organs are dually innervated by the sympathetic (SNS) and parasympathetic (PNS) branches of the autonomic nervous system (ANS). It is well established that SNS hyperactivity occurs in systemic 
hypertension [8,9]. However, more recent evidence has also found increased SNS activity in diabetic individuals, particularly in those with type 2 diabetes [13].

Cardiovascular autonomic neuropathy (CAN) is a common complication of diabetes that is normally associated with dysfunction of both branches of the ANS [28]. The prevalence of CAN has been found to vary [7]; however, if patients with subclinical levels of diabetic CAN are included, the prevalence may in fact exceed $90 \%$ [29]. CAN has been found to manifest first in neurones with longer axons [28]. The vagus nerve is the longest nerve of the ANS, accounting for approximately $75 \%$ of parasympathetic innervation [12]. Recent evidence has found that, in many metabolic diseases, including diabetes, decreased vagal activity may be a key underlying mechanism $[23,30]$.

Although the aetiology of CAN is not yet fully understood, several hypotheses have been purported. One such hypothesis is that prolonged hyperglycaemia in diabetes can lead to the formation of advanced glycation end products (AGEs) [4]. Such AGEs are seen in the glycated haemoglobin $\left(\mathrm{HbA}_{1 \mathrm{c}}\right)$ test that is commonly performed on diabetic individuals to assess their glycaemic control. $\mathrm{HbA}_{1 \mathrm{c}}$ level is an indicator of blood glucose control over the preceding 8-12 weeks. For a comprehensive review of other hypotheses, please refer to Vinik et al. [30].

The haemodynamic response (HDR) is the change in the amount of haemoglobin in a portion of superficial cortex that occurs as a reflex response to increased neuronal activity. It is measured by recording changes in the quantity of haemoglobin in the primary visual cortex (V1) that occur in response to standardised visual stimulation. First described four decades ago [17], functional near-infrared spectroscopy (fNIRS) permits non-invasive measurement of the changes in cortical oxyhaemoglobin [HbO] and deoxyhaemoglobin [HbR] that comprise the HDR. Laser light sources are directed through the scalp and cranium to the cortex, and an adjacent recording 'optode' measures the transcranial emission of light. By selecting 687 and $828 \mathrm{~nm}$ as the wavelengths of recorded light, we can quantify the $[\mathrm{HbO}]$ and $[\mathrm{HbR}]$ within the volume of cortical tissue under observation, and disregard other potential coloured molecules. This technology is complimentary to functional magnetic resonance imaging (fMRI), which maps out changes in metabolites and blood flow [10]. Unlike fMRI, which requires summation of signal over sustained periods of measurement, fNIRS permits the acquisition of data in real time; though, as with visually evoked cortical electrical potentials (VEP), we do average the response over numerous repetitions of the stimulus cycle.

Checkerboards are frequently used simple stimuli that elicit a strong response over V1 [5, 21, 25, 26, 31, 33, 35]. Pattern-reversal checkerboard stimulation has been found to produce stronger cortical activity compared to static checkerboards [33].

The purpose of the current study was to shed light on visual cortical oxygenation in diabetic individuals. We then aimed to compare the HDR to visual stimulation with glycaemic control, given the likelihood of diabetic individuals suffering from macro- and micro-vascular insult.

\section{Methodology}

\section{Stimulus}

The stimulus was a high-contrast pattern-reversal checkerboard that was viewed binocularly at $1 \mathrm{~m}$. The stimulus was displayed on a 19-inch monitor with a screen resolution of $800 \times 600$ pixels. The check size was $30 \mathrm{~min}$ of arc; recent evidence has shown that high-contrast checkerboards with this check size produce the largest increase in [HbO] over the occipital cortex [31]. In accordance with the International Society for Clinical Electrophysiology of Vision (ISCEV) standards, each checkerboard had a temporal frequency of $7.5 \mathrm{~Hz}$ [22]. The stimulus utilised a block design. Initial baseline measures were recorded
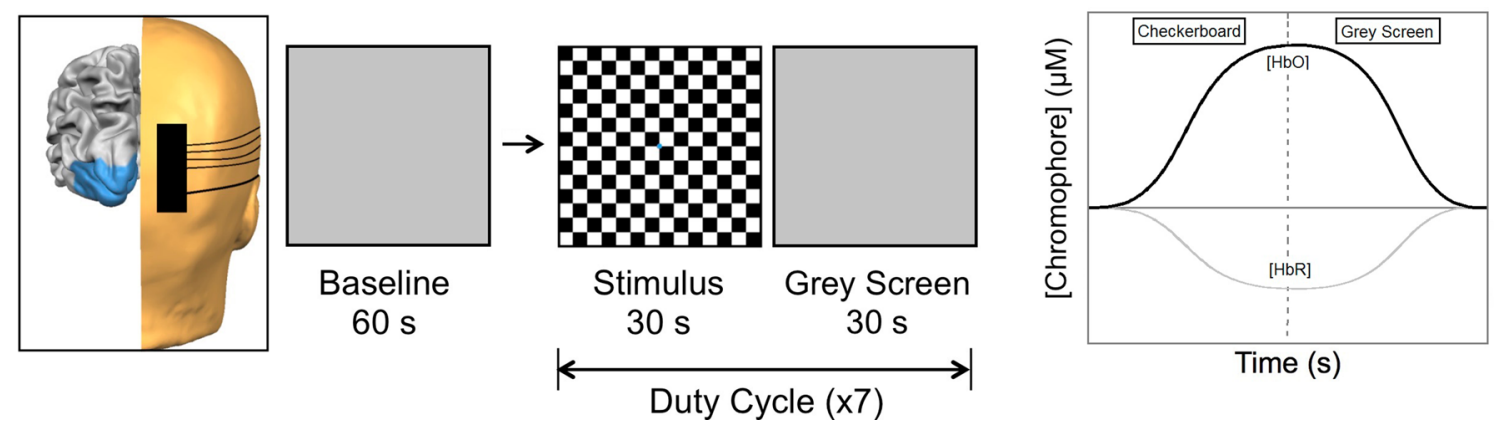

Fig. 1 Stimulus cycle. After baseline, participants viewed a pattern-reversal checkerboard of high contrast, which was then replaced by a grey screen. This was repeated seven times. (Adapted from: Ward et al. [31]) 
for $60 \mathrm{~s}$ prior to the onset of the stimulus, whereby participants viewed an isoluminant grey screen. Seven duty cycles were then presented, with each consisting of $30 \mathrm{~s}$ checkerboard stimulation ('stimulus on') and $30 \mathrm{~s} \mathrm{lumi-}$ nance-matched grey screen ('stimulus off') (Fig. 1).

\section{Apparatus}

A two-channel fNIRS oximeter (OxiplexTS, ISS, Champaign, IL, USA) was used to record the HDR at occipital locations $\mathrm{O}_{1}$ and $\mathrm{O}_{2}$ over V1. The two sensors, each containing four pairs of sources and one optode, were embedded in silicone. This material had a degree of flexibility, which allowed for placement on the scalp. The sources of each sensor were located at fixed distances from the optode, ranging from 1.9 to $3.6 \mathrm{~cm}$. The intensity of the near-infrared (NIR) light emitted at wavelengths 687 and $828 \mathrm{~nm}$ was amplitude modulated at $110 \mathrm{MHz}$, and the sampling rate was $1 \mathrm{~Hz}$. The International 10-20 System of Electrode Placement was used to locate $\mathrm{O}_{1}$ and $\mathrm{O}_{2}$ [16]. Each sensor was placed vertically such that the point that was located midway between the detector and farthest emitter was placed over the region of interest. Although recordings were made over left and right hemispheres, our results consider an average V1 response (please refer to "Effect of hemisphere" below).

\section{Glycated haemoglobin}

$\mathrm{HbA}_{1 \mathrm{c}}$ was measured using the $\mathrm{A}_{1 \mathrm{c}}$ Now ${ }^{\circledR}+$ System (PTS Diagnostics, Indianapolis, IN, USA), which used the principle of colourimetry. This device required a small $5 \mu \mathrm{l}$ capillary blood sample, which was obtained by means of a single-use lancet. Upon application of the sample to the strip, blue micro-particles conjugated to anti- $\mathrm{HbA}_{1 \mathrm{c}}$ antibodies migrated along the reagent strip. The amount of blue microparticles captured on the strip thus reflected the amount of $\mathrm{HbA}_{1 \mathrm{c}}$ in the sample. To determine total haemoglobin ( $\left.\mathrm{THb}\right)$ in the sample, the diluent converted $\mathrm{THb}$ to methaemoglobin (met-Hb). The intensity of the colour of met-Hb measured on the reagent strips was proportional to the concentration of haemoglobin in the sample. Test results were expressed as a percentage [i.e., $\left(\mathrm{HbA}_{1 \mathrm{c}} /\right.$ met- $\left.\left.\mathrm{Hb}\right) \times 100\right]$.

\section{Participants}

We recruited thirty participants, fifteen of whom had diabetes and fifteen of whom were non-diabetic controls. In the diabetic group, the mean age $( \pm S D)$ was $47 \pm 19$ years, and the age range was $20-69$ years. The male-to-female ratio was 8:7. The mean $\mathrm{HbA}_{1 \mathrm{c}}$ level $( \pm \mathrm{SD})$ of the diabetic group was $7.2 \pm 0.6 \%$. The diabetic group comprised five individuals with type 1 diabetes [mean $\mathrm{HbA}_{1 \mathrm{c}}$ level $( \pm \mathrm{SD})$ was $7.7 \pm 0.3 \%$ ] and ten individuals with type 2 diabetes [mean
$\mathrm{HbA}_{1 \mathrm{c}}$ level $( \pm \mathrm{SD})$ was $6.9 \pm 0.6 \%$ ]. The control group had a mean age $( \pm S D)$ of $46 \pm 23$ years, and the age range was 20-71 years. The male-to-female ratio was $7: 8$. The mean $\mathrm{HbA}_{1 \mathrm{c}}$ level $( \pm \mathrm{SD})$ of the control group was $5.5 \pm 0.4 \%$. Both groups were matched for gender [Chi square $\chi^{2}(1$, $n=30)=0.133, p=0.715]$ and age (Mann-Whitney $U$ : $U=95, z=-0.726, p=0.486)$. At $7.2 \pm 0.6 \%$ in the diabetic group and $5.5 \pm 0.4 \%$ in the non-diabetic group, the $\mathrm{HbA}_{1 \mathrm{c}}$ level differed significantly between groups (independent samples $t$ test: $t(28)=8.853, p<0.0005)$. Furthermore, the $\mathrm{HbA}_{1 \mathrm{c}}$ level between individuals with type 1 and type 2 diabetes was significantly different [independent samples $t$ test: $t(13)=2.995, p=0.010]$.

\section{Inclusion and exclusion criteria}

All participants were aged 18 years or older, and had a bestcorrected visual acuity of $0.3 \log$ MAR or better in each eye.

Participants in the diabetic group had either type 1 or 2 diabetes mellitus, and had been diagnosed with the condition for at least 2 years. Furthermore, all diabetic participants reported no diagnosis of diabetic neuropathy (autonomic or peripheral).

Participants with any ocular disease (e.g., cataract, agerelated macular degeneration) or previous damage to V1 (e.g., cerebrovascular accident, trauma) were excluded from the study.

\section{Statistical methods used}

The raw $[\mathrm{HbO}]$ and $[\mathrm{HbR}]$ values that were recorded from each participant were processed using a custom-written MATLAB script (MathWorks Inc., Natick, MA, USA). The following analyses were performed for each participant. The experimental data were normalised to baseline, to control for within-subjects' variance. This was done by subtracting the mean [HbO] and [HbR] recorded during the $60 \mathrm{~s}$ of baseline prior to stimulus onset from each individual value of [HbO] and $[\mathrm{HbR}]$ recorded during stimulus presentation. A moving average filter was then applied to the normalised data. The normalised data were segmented into duty cycles of 'stimulus on' (checkerboard) and 'stimulus off' condition (grey screen), with each 'stimulus on' or 'stimulus off' condition lasting $30 \mathrm{~s}$. The last $15 \mathrm{~s}$ of data from each 'stimulus on' and 'stimulus off' condition were averaged over the seven cycles to give an average 'stimulus on' and 'stimulus off' condition for each participant.

Data were exported to SPSS Statistics 22 (IBM Corp., Armonk, NY, USA). Intraclass correlation analysis was used to assess for hemispheric differences in [HbO] and [HbR] during checkerboard and grey screen, and to assess for interhemispheric differences in $\Delta[\mathrm{HbO}]$ and $\Delta[\mathrm{HbR}]$ between checkerboard and grey screen. Within- and between-group 
analyses were conducted in SPSS Statistics 22. A threeway mixed ANOVA was run to assess how visual stimulation affected [chromophore] in diabetic and non-diabetic groups. We used a two-way mixed ANOVA to assess the $\Delta$ [chromophore] to checkerboard stimulation in diabetic and non-diabetic groups. Multivariate linear regression was used to assess the $\Delta$ [chromophore] as a function of glycaemic control. Effect sizes are reported as partial eta-squared $\left(\eta_{\mathrm{p}}{ }^{2}\right)$ for ANOVA and the square of Pearson's correlation $\left(R^{2}\right)$ for regression.

\section{Results}

\section{Effect of hemisphere}

We found a relationship between the HDRs of $\mathrm{O}_{1}$ and $\mathrm{O}_{2}$ during checkerboard stimulation and grey screen using intraclass correlation analysis. There was also a significant interhemispheric relationship in the change in HDR from grey screen to checkerboard (i.e., 'stimulus on'-'stimulus off') (Table 1). A two-way mixed model with average measures was employed. As the responses of both hemispheres were similar, we used an average $\mathrm{V} 1$ response [i.e., $\left(\mathrm{O}_{1}+\mathrm{O}_{2}\right) / 2$ ].

\section{Effect of stimulation on [chromophore]}

A three-way mixed ANOVA was run to understand how checkerboard stimulation affected [chromophore] in diabetic and non-diabetic groups. The within-subjects' factors were stimulus ('stimulus on' or 'stimulus off') and [chromophore] ([HbO] or [HbR]); the between-subjects' factor was group (diabetic or non-diabetic). There were two outliers for [HbR] during checkerboard stimulation in the non-diabetic group whose value was greater than 1.5 times the interquartile range (>1.5 IQR). The mean value including the outliers was not statistically significantly different to that with the outliers excluded [independent samples $t$ test: $t(26)=0.962, p=0.345]$; therefore, further analysis of this ANOVA included the outliers. [Chromophore] was normally distributed in both groups during 'stimulus on' and 'stimulus off', as assessed by a Shapiro-Wilk test ( $p>0.05)$.

There was a statistically significant three-way interaction between stimulus, [chromophore] and group

Table 1 Intraclass correlation analysis between $\mathrm{O}_{1}$ and $\mathrm{O}_{2}$

\begin{tabular}{llll}
\hline & Stimulus on & Stimulus off & $\Delta$ (On-off $)$ \\
\hline$[\mathrm{HbO}]$ & $\rho=0.670^{* *}$ & $\rho=0.578^{*}$ & $\rho=0.730^{* * *}$ \\
{$[\mathrm{HbR}]$} & $\rho=0.550^{*}$ & $\rho=0.541^{*}$ & $\rho=0.612^{* * *}$ \\
\hline
\end{tabular}

The intraclass correlation coefficient is denoted by $\rho\left({ }^{*} p \leq 0.05\right.$; $* * p \leq 0.01 ; * * * p \leq 0.001)$
$\left[F(1,28)=4.874, p=0.036, \eta_{\mathrm{p}}{ }^{2}=0.148\right]$. The simple twoway interaction between stimulus and [chromophore] was statistically significant in diabetic $[F(1,14)=43.394$, $p<0.0005]$ and non-diabetic groups $[F(1,14)=28.733$, $p<0.0005]$. The simple two-way interaction between stimulus and group was statistically significant for [ $\mathrm{HbO}]$ $[F(1,28)=4.426, p=0.045]$ and $[\mathrm{HbR}][F(1,28)=5.241$, $p=0.030]$.

There was a significant difference between [chromophore] in both diabetic $[F(1,14)=16.519, p=0.001]$ and non-diabetic groups $[F(1,14)=38.754, p<0.0005]$ during checkerboard stimulation (Fig. 2). However, during grey screen presentation ('stimulus off'), [chromophore] did not differ significantly in either group.

During visual stimulation, there was a statistically significant difference in $[\mathrm{HbO}]$ in both diabetic $[F(1,14)=39.581$, $p<0.0005]$ and non-diabetic groups $[F(1,14)=27.629$, $p<0.0005]$. In diabetic individuals, the mean $( \pm \mathrm{SEM})$ [HbO] was $0.25 \pm 0.16 \mu \mathrm{M}$ during grey screen and $1.03 \pm 0.22 \mu \mathrm{M}$ during checkerboard. In non-diabetic individuals, $[\mathrm{HbO}]$ was $0.24 \pm 0.14 \mu \mathrm{M}$ during grey screen and $0.70 \pm 0.11 \mu \mathrm{M}$ during checkerboard. There was also a statistically significant difference in $[\mathrm{HbR}]$ in both diabetic $[F(1,14)=45.242, p<0.0005]$ and non-diabetic groups $[F(1,14)=27.513, p<0.0005]$ in response to visual stimulation. In diabetic individuals, the mean $( \pm$ SEM) $[\mathrm{HbR}]$ was $0.12 \pm 0.07 \mu \mathrm{M}$ during grey screen and $-0.17 \pm 0.08 \mu \mathrm{M}$ during checkerboard, whereas in non-diabetic individuals, [HbR] was $0.02 \pm 0.07 \mu \mathrm{M}$ during grey screen and $-0.14 \pm 0.05 \mu \mathrm{M}$ during checkerboard stimulation.

\section{Effect of diabetes on $\Delta$ [chromophore]}

We then assessed how diabetes affected the change in [chromophore] ( $\Delta$ [chromophore]) to checkerboard stimulation. We did this by means of a two-way mixed ANOVA. $\Delta$ [Chromophore] was calculated as the difference between [chromophore] during checkerboard stimulation and [chromophore] during grey screen (i.e., $\Delta[\mathrm{HbO}]=[\mathrm{HbO}]$ checkerboard- $[\mathrm{HbO}]$ grey screen; $\Delta[\mathrm{HbR}]=[\mathrm{HbR}]$ checkerboard- $[\mathrm{HbR}]$ grey screen). The within-subjects' factor for this ANOVA was $\Delta[$ chromophore $](\Delta[\mathrm{HbO}]$ or $\Delta[\mathrm{HbR}])$; the between-subjects' factor was group (diabetic or nondiabetic). There were no outliers in the data, as assessed by inspection of a boxplot for values $>1.5$ IQR. $\Delta$ [Chromophore] was normally distributed in both groups, as assessed by a Shapiro-Wilk test $(p>0.05)$.

There was a statistically significant two-way interaction between $\Delta$ [chromophore] and group $[F(1,28)=4.874$, $\left.p=0.036, \eta_{\mathrm{p}}{ }^{2}=0.148\right]$. The main effect of $\Delta$ [chromophore] was statistically significant in both diabetic $[F(1,14)=43.394, p<0.0005]$ and non-diabetic groups $[F(1,14)=28.733, p<0.0005]$. Statistical significance 
Fig. 2 Normalised [chromophore]

\section{Occipital HDR During Duty Cycle}

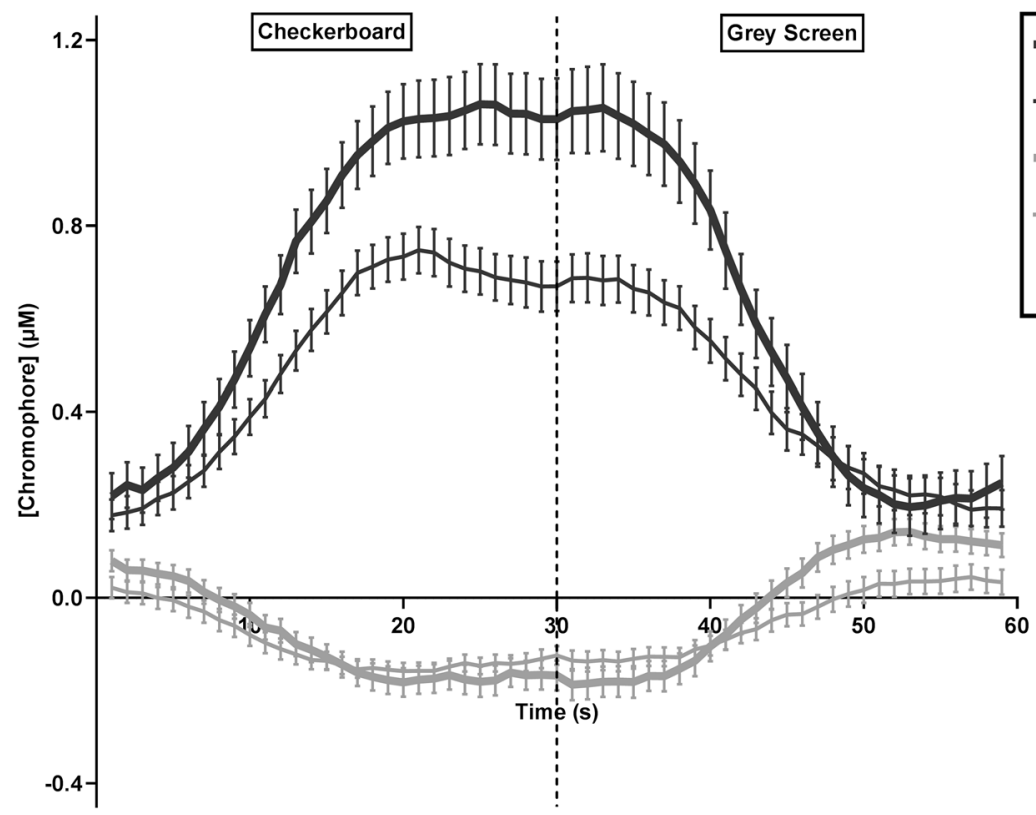

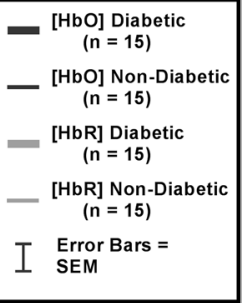

was also found in $\Delta[\mathrm{HbO}]$ between diabetic and nondiabetic groups $[F(1,28)=4.426, p=0.045]$. The mean ( \pm SEM) $\Delta[\mathrm{HbO}]$ was $0.79 \pm 0.11 \mu \mathrm{M}$ in the diabetic group and $0.47 \pm 0.11 \mu \mathrm{M}$ in the non-diabetic group. Similar statistical significance was found in $\Delta[\mathrm{HbR}]$ between groups $[F(1,28)=5.241, p=0.030]$. The mean $( \pm \mathrm{SEM})$ $\Delta[\mathrm{HbR}]$ was $-0.29 \pm 0.04 \mu \mathrm{M}$ in the diabetic group and $-0.17 \pm 0.04 \mu \mathrm{M}$ in the non-diabetic group.

\section{Effect of type of diabetes}

We wanted to separate the effect of type of diabetes on the HDR. We assessed for this by means of a two-way mixed ANOVA in the diabetic group. The within-subjects' factor for this ANOVA was $\Delta$ [chromophore] ( $\Delta[\mathrm{HbO}]$ or $\Delta[\mathrm{HbR}])$; the between-subjects' factor was type of diabetes (type 1 or type 2). There were no outliers in the data, as assessed by inspection of a boxplot for values $>1.5$ IQR. $\Delta$ [Chromophore] was normally distributed in both diabetic subgroups (type 1 and type 2), as assessed by a Shapiro-Wilk test $(p>0.05)$.

A two-way statistically significant interaction was found between $\Delta$ [chromophore] and type of diabetes $\left[F(1,13)=9.882, p=0.008, \eta_{\mathrm{p}}{ }^{2}=0.432\right]$. The main effect of $\Delta$ [chromophore] was statistically significant for both type $1[F(1,4)=106.973, p<0.0005]$ and type 2 subgroups $[F(1,9)=21.081, p=0.001]$.

Statistically significant differences occurred between diabetic subgroups for [chromophore]. There was a statistically significant difference in $\Delta[\mathrm{HbO}]$ between the two subgroups $[F(1,13)=9.414, p=0.009]$. The mean $( \pm$ SEM $)$
$\Delta[\mathrm{HbO}]$ was $1.22 \pm 0.17 \mu \mathrm{M}$ in the type 1 subgroup and $0.57 \pm 0.12 \mu \mathrm{M}$ in the type 2 subgroup. This pattern was repeated for $[\mathrm{HbR}][F(1,13)=7.768, p=0.015]$. The mean ( \pm SEM) $\Delta[\mathrm{HbR}]$ was $-0.43 \pm 0.06 \mu \mathrm{M}$ in the type 1 subgroup and $-0.22 \pm 0.04 \mu \mathrm{M}$ in the type 2 subgroup (Fig. 3).

\section{Effect of glycaemic control}

Multivariate linear regression analysis was run to assess the effect of $\mathrm{HbA}_{1 \mathrm{c}}$ level on $\Delta$ [chromophore]. A scatterplot of $\Delta[\mathrm{HbO}]$ and $\Delta[\mathrm{HbR}]$ against $\mathrm{HbA}_{1 \mathrm{c}}$ was plotted for all diabetic and non-diabetic participants. Visual inspection of this plot indicated a positive linear relationship between $\Delta[\mathrm{HbO}]$ and $\mathrm{HbA}_{1 \mathrm{c}}$. There was also a negative linear relationship between $\Delta[\mathrm{HbR}]$ and $\mathrm{HbA}_{1 \mathrm{c}}$ (Fig. 4). Residuals were normally distributed, as assessed by visual inspection of a normal probability plot.

The prediction equations were as follows: $\Delta[\mathrm{HbO}]=-$ $1.248+0.297 \times \mathrm{HbA}_{1 \mathrm{c}} ; \Delta[\mathrm{HbR}]=0.415-0.102 \times \mathrm{HbA}_{1 \mathrm{c}}$. $\mathrm{HbA}_{1 \mathrm{c}}$ level statistically significantly predicted $\Delta[\mathrm{HbO}]$ $\left[F(1,28)=24.323, p<0.0005, R^{2}=0.465\right]$ and $\Delta[\mathrm{HbR}]$ $\left[F(1,28)=21.752, p=<0.0005, R^{2}=0.437\right] . \mathrm{HbA}_{1 \mathrm{c}}$ thus accounted for $46.5 \%$ of the variation in $\Delta[\mathrm{HbO}]$ and $43.7 \%$ of the variation in $\Delta[\mathrm{HbR}]$. Both of these are large effect sizes [6]. 
Fig. 3 Effect of type of diabetes on $\Delta$ [chromophore] $\left({ }^{*} p \leq 0.05\right.$; $* * p \leq 0.01 ; * * * p \leq 0.001)$

\section{Type of Diabetes}

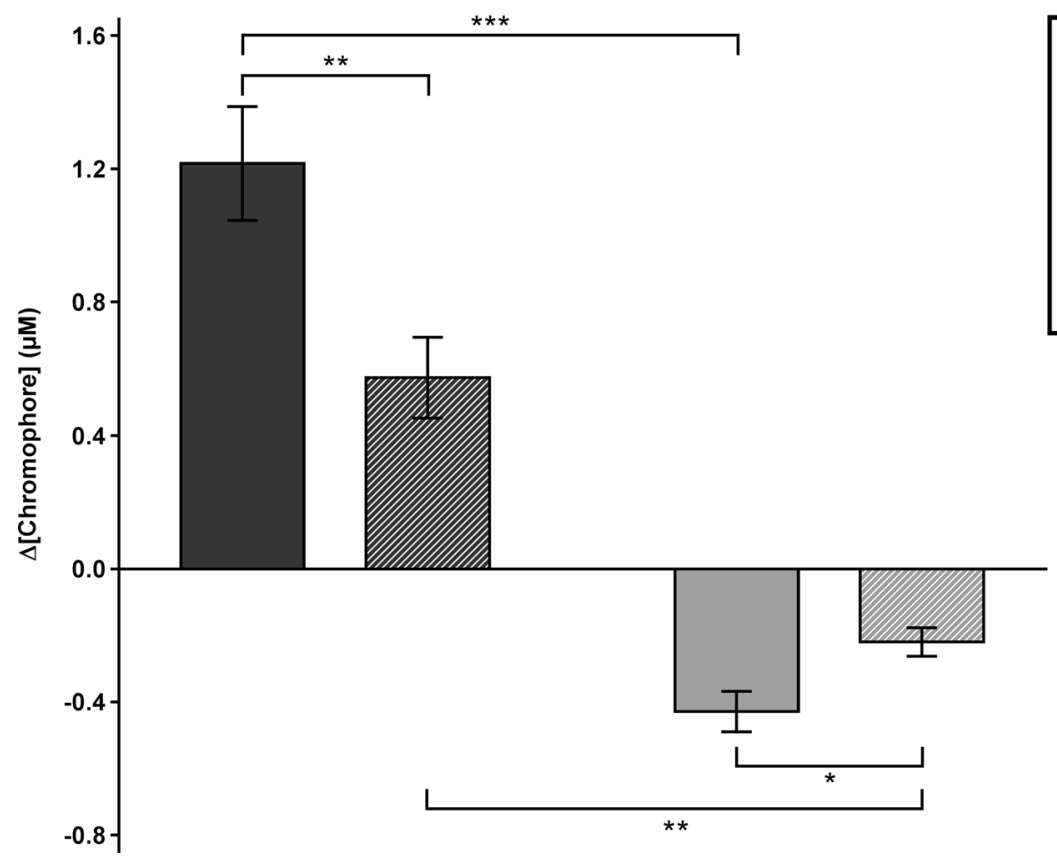

$\Delta\left[\right.$ Chromophore] with $\mathrm{HbA}_{1 \mathrm{c}}$

Fig. 4 Relationship between $\mathrm{HbA}_{1 \mathrm{c}}$ level and $\Delta$ [chromophore]

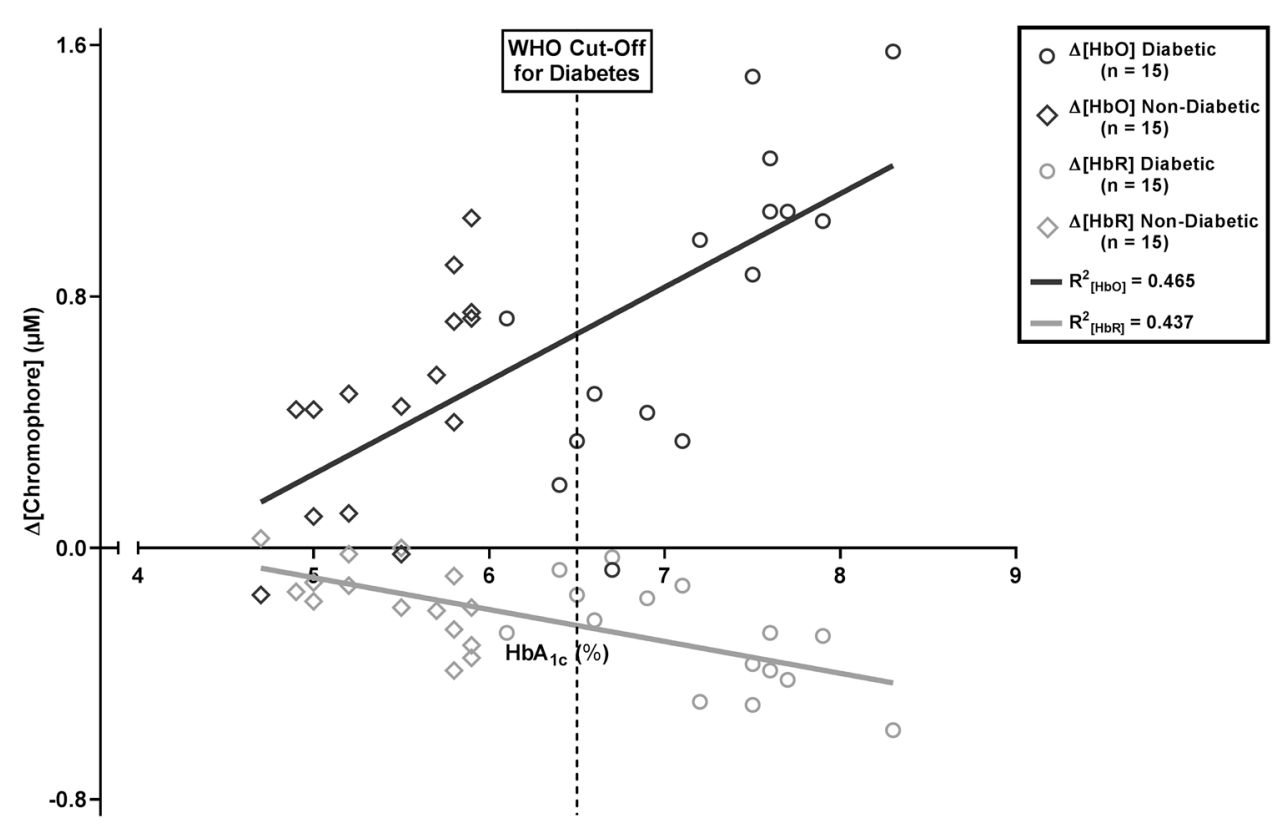

\section{Discussion}

The purpose of this explorative study was to examine the differences in the HDR of diabetic individuals compared to non-diabetic individuals using fNIRS, given the likelihood of diabetic individuals suffering from macro- or microvascular insult. We found that the HDR to checkerboard stimulation took approximately $15 \mathrm{~s}$ to reach its peak, as has been reported in previous studies from this group [20, 31-34]. This was true for both diabetic and non-diabetic individuals. For our statistical analysis, only the last $15 \mathrm{~s}$ of data from each 'stimulus on' and 'stimulus off' condition was used. As the responses of $\mathrm{O}_{1}$ and $\mathrm{O}_{2}$ were similar, our results considered an average $\mathrm{V} 1$ response. 
A characteristic response to visual stimulation was observed, with both diabetic and non-diabetic groups displaying an increased $[\mathrm{HbO}]$ and decreased $[\mathrm{HbR}]$ after onset of the checkerboard stimulus. With neural activity, there is an overall increase in $[\mathrm{HbO}]$ and decrease in [HbR], and much more oxygen is delivered than is consumed. This is a normal physiological mechanism for regional cerebral blood flow control, known as functional hyperaemia, which results in more blood flowing not only to the cortical locations where neurones are most active but also to a much larger area of cortex surrounding the active locations. Malonek and Grinvald [18] eloquently describe this phenomenon as "watering the entire garden for the sake of one thirsty flower'. Our results are in agreement with the findings of previous fNIRS studies [5, 20, $21,25,26,31,33,35]$, all of which have found a similar functional hyperaemic response.

Diabetes is a well-established risk factor for both macroand micro-vascular insult. The chronic complications of diabetes and vascular disease are closely intertwined in their pathogeneses. It is important for the relationship between diabetes and vascular disease to be better understood, given that the prevalence of diabetes is projected to continue to increase in the coming decades [15]. Our group analysis found that participants with diabetes had a significantly larger HDR compared to non-diabetic controls. This was reflected not only as an increase in delivery of arterial $[\mathrm{HbO}]$, but there was also a difference in $[\mathrm{HbR}]$, which is an indicator of venous return. Individuals with type 1 diabetes were found to have a larger HDR compared to those with type 2 diabetes. Moreover, we found a linear relationship between participants' $\mathrm{HbA}_{1 \mathrm{c}}$ level and $\mathrm{HDR}$, with there being an increase in $\Delta[\mathrm{HbO}]$ and decrease in $\Delta[\mathrm{HbR}]$ as a function of their glycaemic control. $\mathrm{HbA}_{1 \mathrm{c}}$ accounted for $46.5 \%$ of the variation in $\Delta[\mathrm{HbO}]$ and $43.7 \%$ of the variation in $\Delta[\mathrm{HbR}]$, both of which are large effect sizes [6]. However, our results from diabetic individuals with chronic hyperglycaemia differ from those of an fMRI study, in which the authors found no substantial effect on activation of the occipital cortex in non-diabetic individuals with induced acute hyperglycaemia [11]. Perhaps the normal functioning of the ANS of non-diabetic individuals may be responsible for this. The ANS of diabetic individuals is generally chronically compromised; therefore, a short period of induced hyperglycaemia in non-diabetic individuals would not necessarily mimic a diabetic response.

There are two hypotheses for this apparently linear relationship between HDR and glycaemic control, both of which involve ANS dysfunction; these are over-action of the SNS and under-action of the PNS. It is well established that SNS hyperactivity occurs in systemic hypertension $[8,9]$ and is involved in the pathogenesis of the macro- and microvascular damage that ensues [19]. Systemic hypertension coexists in $80 \%$ of cases of type 2 diabetes and in $25 \%$ of cases of type 1 diabetes [3]. The presence of systemic hypertension in diabetes is known to augment macro- and microvascular insult [14]; even in normotensive individuals with type 2 diabetes, SNS activity is higher than in non-diabetic individuals [13]. Although SNS over-action may help us to understand why en bloc diabetic individuals had a higher HDR compared to their non-diabetic counterparts, it does not account for the larger HDR found in individuals with type 1 diabetes compared to those with type 2 diabetes.

Another hypothesis is that higher than normal arterial blood flow to the visual areas in response to visual stimulation could be an indicator of CAN. Poor glycaemic control is a major risk factor for the development of CAN in diabetes [36]. Although it is a disorder associated with dysfunction of both branches of the ANS, CAN has been found to manifest first in neurones with longer axons [28]. The vagus nerve is the longest nerve of the ANS, accounting for approximately $75 \%$ of parasympathetic innervation in the body [12]. Recent evidence has found that, in many metabolic diseases, including diabetes, decreased vagal activity may be a key underlying mechanism [30]. Early in the course of the disease, CAN tends to be associated with PNS denervation, and the SNS branch predominates with reduced opposition from the PNS. This alters the SNS-PNS tone, and a compensatory increase in the cardiac sympathetic tone ensues [24, 27]. Although we cannot prove causality, it can be hypothesised that the increased HDR as a function of glycaemic control may be due to ANS dysfunction, either by over-action of the SNS or under-action of the PNS.

Most diabetic individuals in this study had relatively good glycaemic control, in that the highest $\mathrm{HbA}_{1 \mathrm{c}}$ level recorded from any participant was $8.3 \%$. Future studies should aim to include diabetic participants with elevated or severely elevated $\mathrm{HbA}_{1 \mathrm{c}}$ levels. This would be with a view to determining: (1) whether the HDR continues to increase linearly as a function of glycaemic control, which may suggest overaction of the SNS; (2) whether the HDR reaches a plateau at given $\mathrm{HbA}_{1 \mathrm{c}}$ level; (3) whether the HDR reduces as the SNS branch also becomes affected in the course of CAN progression. In addition, other measures of autonomic activity should be included, such as heart rate and blood pressure. Heart rate variability would be another such measure, as it has been found to be directly linked to parasympathetic vagal activity [2]. Furthermore, in order for the results to be generalisable to the population, future studies should include many more participants from various centres.

In conclusion, our findings suggest that fNIRS can be used as a quantitative technique to measure cerebral oxygenation in diabetes. We have found that diabetic individuals have a larger HDR (reflected as increased $\Delta[\mathrm{HbO}]$ and decreased $\Delta[\mathrm{HbR}]$ to visual stimulation) compared to nondiabetic individuals. These $\Delta[\mathrm{HbO}]$ and $\Delta[\mathrm{HbR}]$ appear to 
be correlated with $\mathrm{HbA}_{1 \mathrm{c}}$ level. The apparently linear relationship between HDR and glycaemic control may be due to ANS dysfunction.

\section{Compliance with ethical standards}

Conflict of interest All Authors declare that they have no conflict of interest.

Statement of human and animal rights All procedures followed were in accordance with the ethical standards of the responsible committee on human experimentation (institutional and national) and with the Helsinki Declaration of 1975, as revised in 2008 (5).

Statement of informed consent Informed consent was obtained from all patients for being included in the study.

Open Access This article is distributed under the terms of the Creative Commons Attribution 4.0 International License (http://creativeco mmons.org/licenses/by/4.0/), which permits unrestricted use, distribution, and reproduction in any medium, provided you give appropriate credit to the original author(s) and the source, provide a link to the Creative Commons license, and indicate if changes were made.

\section{References}

1. American Diabetes Association (2009) Diagnosis and classification of diabetes mellitus. Diabetes Care 32(Suppl 1):S62-S67. http://www.ncbi.nlm.nih.gov/pubmed/19118289. Accessed 28 July 2016

2. Berntson GG et al (1997) Heart rate variability: origins, methods, and interpretive caveats. Psychophysiology 34(6):623-648. http:// www.ncbi.nlm.nih.gov/pubmed/9401419. Accessed 5 July 2017

3. Blood Pressure Association (2008) Blood pressure UK: diabetes and high blood pressure. http://www.bloodpressureuk.org/Blood Pressureandyou/Yourbody/Diabetes. Accessed 19 July 2017

4. Brownlee M, Vlassara H, Cerami A (1984) Nonenzymatic glycosylation and the pathogenesis of diabetic complications. Ann Intern Med 101(4):527-537. http://www.ncbi.nlm.nih.gov/pubme d/6383165. Accessed 7 Aug 2016

5. Caffini M et al (2012) Functional near infrared spectroscopy and diffuse optical tomography in neuroscience. In: Chaudhary V (ed) Advances in brain imaging. InTech, pp 52-76

6. Cohen J (1988) Statistical power analysis for the behavioral sciences, 2nd edn. Lawrence Erlbaum Associates, Hillsdale

7. Dimitropoulos G, Tahrani AA, Stevens MJ (2014) Cardiac autonomic neuropathy in patients with diabetes mellitus. World J Diabetes 5(1):17-39. http://www.ncbi.nlm.nih.gov/pubmed/24567 799. Accessed 29 Sept 2016

8. Esler M (2000) The sympathetic system and hypertension. Am J Hypertens 13(6 Pt 2):99S-105S. http://www.ncbi.nlm.nih.gov/ pubmed/10921528. Accessed 20 July 2017

9. Grassi G (1998) Role of the sympathetic nervous system in human hypertension. J Hypertens 16(12 Pt 2):1979-1987. http://www. ncbi.nlm.nih.gov/pubmed/9886886. Accessed 20 July 2017

10. Gratton G, Fabiani M (2001) The event-related optical signal: a new tool for studying brain function. Int J Psychophysiol Off J Int Organ Psychophysiol 42(2):109-121. http://www.ncbi.nlm.nih. gov/pubmed/11587771. Accessed 7 Aug 2016

11. Gruetter R, U? urbil K, Seaquist ER (2000) Effect of acute hyperglycemia on visual cortical activation as measured by functional
MRI. J Neurosci Res 62(2):279-285. http://www.ncbi.nlm.nih. gov/pubmed/11020220. Accessed 21 July 2017

12. Guyton AC, Hall JE (2000) Textbook of medical physiology, 10th edn. W. B. Saunders Company, Philadelphia

13. Huggett RJ (2003) Impact of Type 2 diabetes mellitus on sympathetic neural mechanisms in hypertension. Circulation 108(25):3097-3101. http://circ.ahajournals.org/cgi/ doi/10.1161/01.CIR.0000103123.66264.FE. Accessed 20 July 2017

14. Hypertension in Diabetes Study (1993) Hypertension in Diabetes Study (HDS): II. Increased risk of cardiovascular complications in hypertensive type 2 diabetic patients. J Hypertens 11(3):319-325. http://www.ncbi.nlm.nih.gov/pubmed/8387090. Accessed 20 July 2017

15. International Diabetes Federation (2015) IDF diabetes atlas, 7th edn. International Diabetes Federation, Brussels

16. Jasper HH (1958) Report of the committee on methods of clinical examination in electroencephalography: 1957. Electroencephalogr Clin Neurophysiol 10(2):370-375

17. Jöbsis FF (1977) Noninvasive, infrared monitoring of cerebral and myocardial oxygen sufficiency and circulatory parameters. Science (New York) 198(4323):1264-1267. http://www.ncbi.nlm. nih.gov/pubmed/929199. Accessed 7 Aug 2016

18. Malonek D, Grinvald A (1996) Interactions between electrical activity and cortical microcirculation revealed by imaging spectroscopy: implications for functional brain mapping. Science (New York) 272(5261):551-554. http://www.ncbi.nlm.nih.gov/ pubmed/8614805. Accessed 21 July 2017

19. Mancia G et al (1999) Sympathetic activation in the pathogenesis of hypertension and progression of organ damage. Hypertension 34(4):724-728. http://hyper.ahajournals.org/conte $\mathrm{nt} / 34 / 4 / 724$ ? ijkey $=325416 \mathrm{a} 43$ ef7934fe73c61b98e2452ee $1 \mathrm{~b} 4$ 79bea\&keytype2=tf_ipsecsha. Accessed 20 July 2017

20. McIntosh MA et al (2010) Absolute quantification of oxygenated hemoglobin within the visual cortex with functional near infrared spectroscopy (fNIRS). Investig Opthalmol Vis Sci 51(9):4856

21. Obrig $\mathrm{H}$ et al (2000) Spontaneous low frequency oscillations of cerebral hemodynamics and metabolism in human adults. NeuroImage 12(6):623-639

22. Odom JV et al (2010) ISCEV standard for clinical visual evoked potentials (2009 update). Doc Ophthalmol 120(1):111-119

23. Plachta DTT et al (2014) Blood pressure control with selective vagal nerve stimulation and minimal side effects. J Neural Eng 11(3):036011. http://www.ncbi.nlm.nih.gov/pubmed/24809832. Accessed 21 July 2017

24. Pop-Busui R et al (2004) Sympathetic dysfunction in type 1 diabetes. J Am Coll Cardiol 44(12):2368-2374. http://www.ncbi.nlm. nih.gov/pubmed/15607400. Accessed 30 June 2017

25. Remijn GB et al (2011) Hemodynamic responses to visual stimuli in cortex of adults and 3- to 4-year-old children. Brain Res 1383:242-251

26. Sun B et al (2014) Detection of optical neuronal signals in the visual cortex using continuous wave nearinfrared spectroscopy. NeuroImage 87:190-198

27. Taskiran M et al., 2004. Left ventricular dysfunction in normotensive Type 1 diabetic patients: the impact of autonomic neuropathy. Diabet Med 21(6):524-530. http://www.ncbi.nlm.nih.gov/pubme d/15154934. Accessed 30 June 2017

28. Vinik AI et al (2003) Diabetic autonomic neuropathy. Diabetes Care 26(5):1553-1579

29. Vinik AI et al (1992) Diabetic neuropathies. Diabetes Care 15(12):1926-1975. http://www.ncbi.nlm.nih.gov/pubmed/14642 46. Accessed 20 Oct 2016

30. Vinik AI, Erbas T, Casellini CM (2013) Diabetic cardiac autonomic neuropathy, inflammation and cardiovascular disease. $\mathrm{J}$ 
Diabetes Investig 4(1):4-18. http://www.ncbi.nlm.nih.gov/pubme d/23550085. Accessed 21 July 2017

31. Ward LM et al (2015) Reduced haemodynamic response in the ageing visual cortex measured by absolute fNIRS. Plos One 10(4): 0125012

32. Ward LM et al (2016) Using functional near infrared spectroscopy (fNIRS) to study dynamic stereoscopic depth perception. Brain Topogr 29(4):515-523. http://link.springer.com/10.1007/s1054 8-016-0476-4. Accessed 7 Aug 2016

33. Wijeakumar S, Shahani U, Simpson WA et al (2012) Localization of hemodynamic responses to simple visual stimulation: an fNIRS study. Investig Opthalmol Vis Sci 53(4):2266. http://iovs.arvoj ournals.org/article.aspx?doi=10.1167/iovs.11-8680. Accessed 7 Aug 2016
34. Wijeakumar S, Shahani U, McCulloch DL et al (2012) Neural and vascular responses to fused binocular stimuli: a VEP and fNIRS study. Investig Opthalmol Vis Sci 53(9):5881. http://iovs.arvoj ournals.org/article.aspx?doi=10.1167/iovs.12-10399. Accessed 7 Aug 2016

35. Wobst $\mathrm{P}$ et al (2001) Linear aspects of changes in deoxygenated hemoglobin concentration and cytochrome oxidase oxidation during brain activation. NeuroImage 13(3):520-530

36. Ziegler D et al (1993) Prevalence and clinical correlates of cardiovascular autonomic and peripheral diabetic neuropathy in patients attending diabetes centers. The Diacan Multicenter Study Group. Diabète Métabolisme 19(1 Pt 2):143-151. http://www.ncbi.nlm. nih.gov/pubmed/8314418. Accessed 29 Sept 2016 